\title{
Arang Keshavarzian
}

\author{
REGIME LOYALTY AND $B \bar{A} Z \bar{A} R \bar{I}$ \\ REPRESENTATION UNDER THE ISLAMIC \\ REPUBLIC OF IRAN: DILEMMAS OF THE \\ SOCIETY OF ISLAMIC COALITION
}

Tracing the political trajectory of the Society of Islamic Coalition Association (SIC) since the Islamic Revolution, this paper explains the party's poor electoral performance and its increasingly

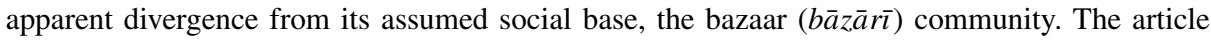
argues that SIC organization and behavior are influenced by the experiences of the prerevolutionary era and state institutions of the Islamic republic. SIC's initial position of power was associated with its members' long-standing relations with the founders of the regime. However, this ultimately laid the foundation for its unwillingness and inability to develop an institutionalized party structure with a social base. As a consequence, $b \bar{a} z \bar{a} r \bar{\imath}$ s have increasingly been alienated from the party leadership and unable to represent their group interests in institutional politics. The analytical narrative incorporates insights from institutionalist approaches to authoritarian politics and presents a view of Iranian political history that stresses contingency, fluidity, and pragmatism in political decision making by elites. 